\title{
Influence of Process Parameters on the RF Sputtered GaP Thin Films
}

\author{
D.A. Mota ${ }^{1,2)}$, G. Hema Chandra ${ }^{1,3)}$, J. Ventura ${ }^{2)}$, A. Guedes $^{4)}$, J. Pérez de la Cruz ${ }^{1)^{*}}$ \\ 1) INESC TEC, Rua do Campo Alegre $n^{\circ}$ 687, 4169-007 Porto, Portugal \\ 2) IFIMUP-IN, Rua do Campo Alegre $n^{\circ}$ 687, 4169-007 Porto, Portugal \\ 3) Thin Film Laboratory, Material Physics Division, VIT University, Vellore 632 014, India \\ 4) Geology Department, Faculty of Science, University of Porto, Rua do Campo Alegre n ${ }^{\circ}$ 687, 4169-007 Porto, Portugal \\ [Manuscript received August 7, 2012, in revised form November 29, 2012, Available online 26 June 2013]
}

\begin{abstract}
In this work, gallium phosphide thin films were deposited on glass substrates by radio frequency (RF) magnetron sputtering technique under different depositions conditions. The X-ray diffraction analysis showed a diversity of states: from amorphous in the films deposited at $175^{\circ} \mathrm{C}$ to a nearly stoichiometric and polycrystalline films, exhibiting cubic phase with preferred orientation along (220), in the films deposited at temperatures higher than $250{ }^{\circ} \mathrm{C}$. Scanning electron microscopy images revealed that all films were uniform with a smooth surface, while the energy-dispersive spectroscopy (EDS) analysis showed that there was a visible dependence on the $\mathrm{Ga} / \mathrm{P}$ ratio in the deposition conditions and confirmed that a residual $\mathrm{Ga}$ metallic phase was presented in the surface of all the films. The Raman analysis showed the structural evolution of the GaP films was strongly dependent on the deposition conditions. The conductivity of the films was slightly dependent on the argon pressure and the rf power, but strongly dependent on the deposition temperature, mainly above $200{ }^{\circ} \mathrm{C}$. The optical transmission and absorption analyses of the GaP films revealed an indirect band gap of $\sim 1.70 \mathrm{eV}$ in the films deposited at temperatures less than $200{ }^{\circ} \mathrm{C}$, which transited to a band gap of $2.26 \mathrm{eV}$ as the deposition temperature was close to $300{ }^{\circ} \mathrm{C}$.
\end{abstract}

KEY WORDS: Gallium phosphide; Thin films; Sputtering; Amorphous; Band gap

\section{Introduction}

Amorphous III-V semiconductors, like their crystalline counterparts, show electroluminescence effects, and this property in conjunction with the possibility to produce low-cost large-area films gives rise to materials particularly promising for optoelectronic applications ${ }^{[1,2]}$. In contrast with amorphous silicon (a-Si) technology, which generated a wide range of applications, such as photovoltaic solar cells, thin film transistors and photodiodes $^{[3]}$, a relative lower interest has been devoted to amorphous III-V semiconductors.

Among all the III-V semiconductors, gallium phosphide (GaP) is an excellent candidate to be part of a high band gap solar cell in a multijunction system, due to its band gap $(2.26 \mathrm{eV})$ and well developed grown technology by epitaxial techniques ${ }^{[4]}$. It has usually been grown in crystalline form by using epitaxial techniques, mainly for applications in optical devices, light-emitting diodes (LEDs), photo cells, and it is one of the most promising

\footnotetext{
* Corresponding author. Ph.D.; Tel.: +351 22 0402301; Fax: +351 22 0402437; E-mail address: jcruz@inescporto.pt (J. Pérez de la Cruz). 1005-0302/\$ - see front matter Copyright @ 2013, The editorial office of Journal of Materials Science \& Technology. Published by Elsevier Limited. All rights reserved.

http://dx.doi.org/10.1016/j.jmst.2013.06.005
}

materials for development of solar cells ${ }^{[1,5]}$. Moreover, GaP-based ternary and quaternary compound semiconductors, such as InGaP and AlInGaP, provide several interesting properties which are suitable for multijunction solar cell applications ${ }^{[6]}$.

In contrast with a-Si, amorphous $\mathrm{GaP}(\mathrm{a}-\mathrm{GaP})$ has a variety of localized states, like wrong bonds or dangling bonds with respect to the individual elements (III and V elements) of its composition and coordination ${ }^{[7]}$. For that reason, a-GaP has been used in applications, such as LEDs and high-temperature transistors ${ }^{[8]}$. The flexibility of its energy gap should be useful for tuning widearea tandem solar cells in the near future ${ }^{[7]}$. In the photovoltaic field, a-GaP has the advantages of being relatively cheap, low temperature deposition and the possibility of growth on a variety of substrates, including glass, metal and plastic, with diverse commercial applications ${ }^{[9]}$; being its visible light absorption higher than that reported for crystalline structure ${ }^{[10]}$.

As mentioned above, epitaxial techniques have mainly been used to obtain crystalline $\mathrm{GaP}$ thin films; however, several deposition methods have also been used for the preparation of amorphous and crystalline GaP thin films, like plasma enhanced chemical transport deposition (PECTD) ${ }^{[11]}$, evaporation $^{[10,12-14]}$, plasma deposition ${ }^{[15]}$, liquid phase epitaxy $(\mathrm{LPE})^{[4,16]}$, ion beam assisted deposition ${ }^{[7]}$ and sputtering ${ }^{[5,17-}$ ${ }^{22]}$. Among these deposition techniques, radio frequency (rf) sputtering is known to be suitable for large-scale applications in device fabrication at a relatively low cost ${ }^{[20]}$. Compared with 
other deposition techniques, rf sputtering does not involve high temperature deposition, in both source material and substrate, which is particularly advantageous as it is known that the atomic bond between $\mathrm{Ga}$ and $\mathrm{P}$ dissociates at high temperatures, resulting in the volatilization of the phosphorous ${ }^{[5]}$.

Although there are a few reports on GaP films by rf sputtering, most of them have just focused on the effects of the substrate temperature on the optical properties. Moreover, the GaP thin film preparation conditions reported are not consistent among them.

For this reason, in this paper we report large spectra of deposition conditions, where the GaP thin films were deposited on glass substrates by rf magnetron sputtering under different argon partial pressures in the chamber, rf source powers and substrate temperatures. Moreover, the structure, composition, morphology, together with the electrical and optical properties of the deposited $\mathrm{GaP}$ thin films are analysed in order to evaluate the potential of sputtered films to be integrated in the fabrication of concentrator solar cells.

\section{Experimental}

The films were prepared by $\mathrm{rf}$ magnetron sputtering by using a $50.8 \mathrm{~mm}$ ( 2 inch) diameter and $5 \mathrm{~mm}$ thick undoped n-type $<100>$ oriented $\mathrm{GaP}$ polycrystalline target, with an average target-to-substrate distance of $5 \mathrm{~cm}$. All the depositions were carried out in argon atmosphere, starting under a typical chamber pressure of $5 \times 10^{-4} \mathrm{~Pa}$. In order to eliminate contaminants and to clean the surface of the target, a pre-sputtering process was carried out for $10 \mathrm{~min}$ at an argon chamber pressure of $1.2 \mathrm{~Pa}$. Afterwards, the films were deposited on cleaned glass substrates under several preparation conditions. To optimize the deposition conditions, three different sets of films (A, B and C) were prepared by changing a specific parameter, while the others remain constant. The values of the deposition parameters are reported in Table 1. At the end of each deposition, the substrate temperature was kept constant for $15 \mathrm{~min}$, with the objective to remove some of the defects that might occur during the deposition process. The film thickness was controlled by using a quartz crystal monitor, keeping it constant at $400 \mathrm{~nm}$. The substrate temperature was monitored and controlled by a proportional integral derivative (PID) temperature controller (Eurotherm 2408) by using a k-type thermocouple placed near the substrates.

The crystallinity of the films was analysed by using a Philips $\mathrm{X}$-ray diffractometer with $\mathrm{CuK \alpha}$ radiation $(\lambda=0.15406 \mathrm{~nm})$. The patterns were recorded in continuous mode in the $2 \theta$ range of $20^{\circ}-80^{\circ}$ with a scan step of $0.017^{\circ}$. The Raman spectra were recorded by using a Jobin-Yvon LabRaman spectrometer. A HeNe laser of $632.8 \mathrm{~nm}$ was used giving a monochromatic red light at a working power of $20 \mathrm{~mW}$. The unpolarized Raman studies of the films were carried out in the $200-800 \mathrm{~cm}^{-1}$ frequency range, with the samples placed in a micro-Raman set-up.

The elemental composition of the films was determined by an energy-dispersive X-ray spectroscope detector attached to an

Table 1 Summary of the parameters used in different deposition runs

\begin{tabular}{cccccc}
\hline Sets & $\begin{array}{c}\text { Argon } \\
\text { pressure } \\
(\mathrm{Pa})\end{array}$ & $\begin{array}{c}\text { Rf power } \\
(\mathrm{W})\end{array}$ & $\begin{array}{c}\text { Substrate } \\
\text { temperature }\left({ }^{\circ} \mathrm{C}\right)\end{array}$ & $\begin{array}{c}\text { Deposition } \\
\text { rate }(\mathrm{nm} / \mathrm{s})\end{array}$ & $\begin{array}{c}\text { Self-bias } \\
\text { voltage }(\mathrm{V})\end{array}$ \\
\hline $\mathrm{A}$ & $0.3-1.0$ & 100 & 175 & $0.39-0.55$ & $243-381$ \\
$\mathrm{~B}$ & 0.4 & $40-200$ & 175 & $0.20-0.74$ & $245-575$ \\
$\mathrm{C}$ & 0.4 & 80 & $25-400$ & $0.30-0.35$ & 354 \\
\hline
\end{tabular}

FEI Quanta 400 FEG ESEM scanning electron microscope. The optical transmittance and reflectance of the films were recorded at room temperature in the $300-1050 \mathrm{~nm}$ wavelength range by using a Hitachi U-2010 UV-Vis double beam spectrophotometer and a Shimadzu UV-2101PC UV-vis-NIR spectrophotometer, respectively. The conductivity of the films was measured at room temperature by using standard four-point technique.

\section{Results and Discussion}

\subsection{GaP amorphous films}

3.1.1. Structural analysis. Fig. 1(a) shows the X-ray diffraction (XRD) patterns of GaP films deposited at several chamber argon pressures $\left(p_{\mathrm{Ar}}=0.3-1.0 \mathrm{~Pa}\right)$, while the rf power $\left(P_{\mathrm{rf}}\right)$ and the substrate temperature during the deposition $\left(T_{\mathrm{s}}\right)$ remain constant at $100 \mathrm{~W}$ and $175{ }^{\circ} \mathrm{C}$, respectively (set A). As expected, the XRD spectra analysis shows that all the films deposited at these sputtering pressures are amorphous; however, some weak diffraction peaks are observed. These peaks observed in the A sample are attributed to the (111), (221) and (151) diffraction planes of the orthorhombic gallium (Ga) phase, which are in good agreement with the results reported by Curien et al. ${ }^{[23]}$ and Bruzzone ${ }^{[24]}$, respectively. The Ga phase is
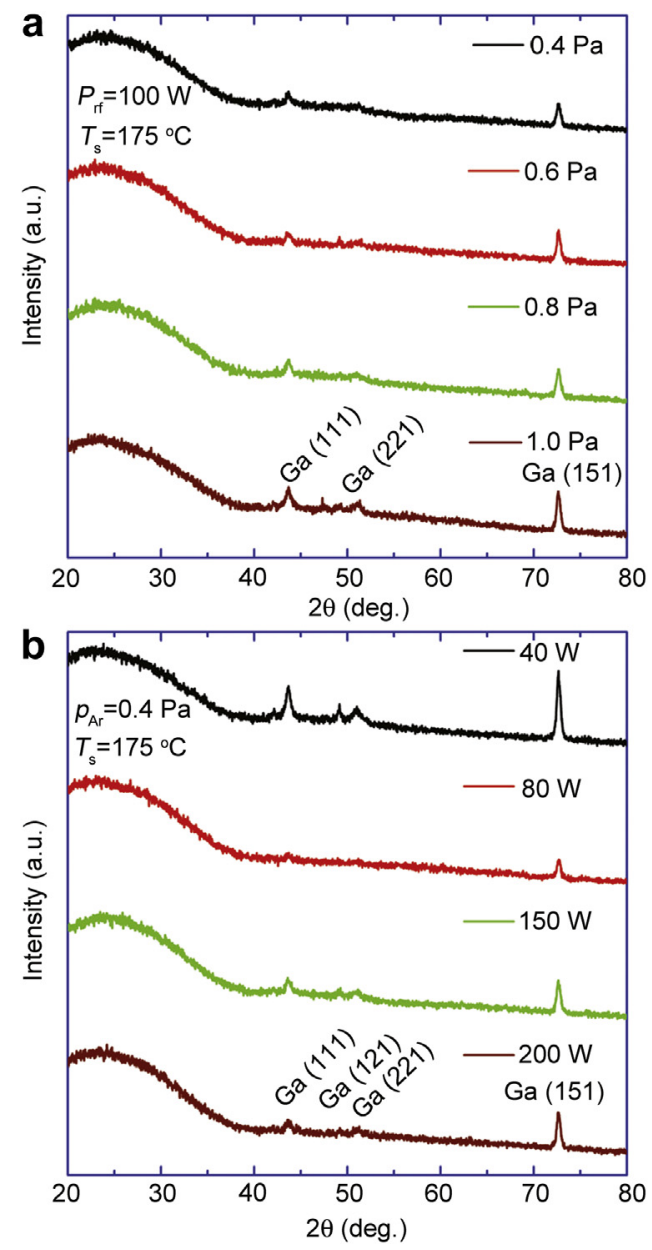

Fig. 1 X-ray diffraction spectra of a-GaP thin films deposited at different argon deposition pressures (a) and rf deposition powers (b). 

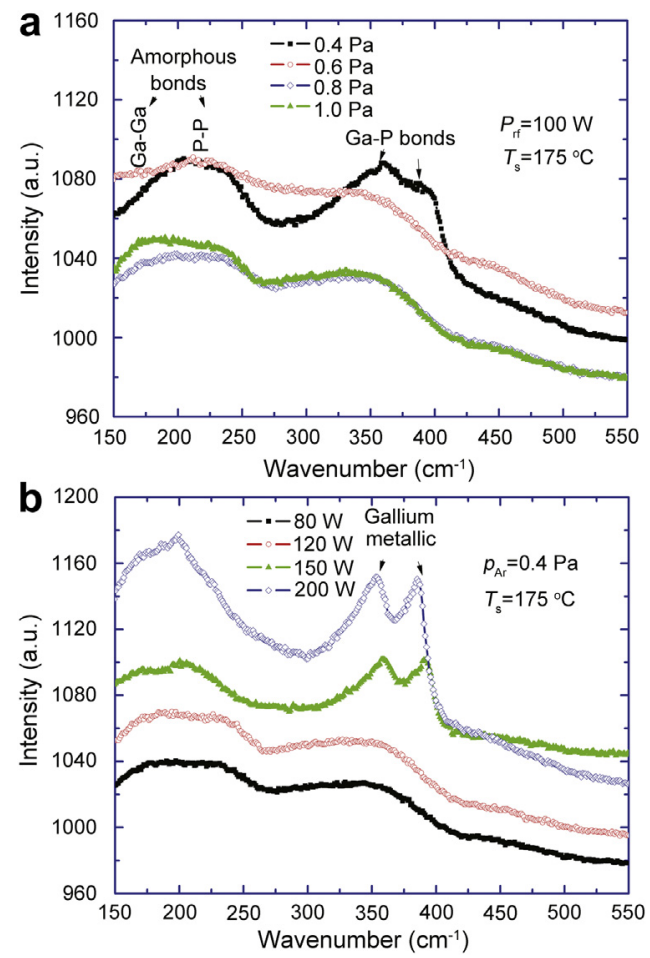

Fig. 2 Raman spectra of a-GaP thin films deposited at different argon deposition pressures (a) and $\mathrm{rf}$ deposition powers (b).

found to be suppressed with the decrease in sputtering argon pressure, being practically not observed on the A sample deposited at $0.3 \mathrm{~Pa}$ (unshown). It is believable that the decrease of the argon pressure employed in the deposition process reduces the scattering effect of the sputtered atoms in the gas phase, which results in a lower interaction of the simple ions avoiding the formation of residual phases such as metallic gallium and phosphorous.

XRD patterns of the GaP films deposited at $p_{\mathrm{Ar}}=0.4 \mathrm{~Pa}$ and $T_{\mathrm{s}}=175{ }^{\circ} \mathrm{C}$ by using several $\mathrm{rf}$ powers (set B) are shown in Fig. 1(b). All the films show a residual Ga phase with no significant modifications in the amorphous $\mathrm{GaP}$ and residual $\mathrm{Ga}$ phases as the rf power used in the deposition process is changed from 60 up to $200 \mathrm{~W}$. However, at the lowest rf power $\left(P_{\mathrm{rf}}=40 \mathrm{~W}\right)$, a more intensive Ga phase and two unidentified reflection peaks at $2 \theta=42.16^{\circ}$ and $49^{\circ}$ are observed. This behaviour is associated with the lower kinetic energy that is supplied to the atoms at this rf power, allowing the formation of Ga-rich phases. The result is consistent with that observed at naked eye in the B samples, which reveal that they are nontransparent with a metallic shiny appearance.
Fig. 2(a) and (b) shows the Raman spectra of selected A and B samples, respectively. It is visible (Fig. 2(a)) that there is an improvement in the $300-400 \mathrm{~cm}^{-1}$ gallium and phosphorous bands at a gas chamber pressure of $0.4 \mathrm{~Pa}$ and a shift to higher frequency of wider $150-250 \mathrm{~cm}^{-1}$ band related to $\mathrm{Ga}-\mathrm{Ga}, \mathrm{Ga}-\mathrm{P}$ and $\mathrm{P}-\mathrm{P}$ bonds. This behaviour is consistent with the improvement of the stoichiometry at this pressure. On the other hand, in films prepared at different $\mathrm{rf}$ power there is an evolution of the 354 and $385 \mathrm{~cm}^{-1}$ gallium bands above $120 \mathrm{~W}$ that is consistent with the formation of a superficial gallium metallic layer. Although a crystalline gallium phase formed, the Raman analysis of these samples did not show the formation of the GaP crystalline bands in agreement with the $\mathrm{X}$-ray results.

3.1.2. Compositional analysis. Fig. 3(a) shows a representative energy-dispersive spectroscopy (EDS) analysis pattern of the $\mathrm{GaP}$ films deposited at $0.4 \mathrm{~Pa}$, keeping the rf source power at $80 \mathrm{~W}$ and substrate temperature at $175^{\circ} \mathrm{C}$. The film grown at these conditions is almost stoichiometric, with $53.3 \%$ of gallium and $46.7 \%$ of phosphorous, which is comparable to the starting material composition $\left(\mathrm{Ga}_{1-x} \mathrm{P}_{x}\right.$, with $\left.x=0.5\right)$ and to the composition of $\mathrm{GaP}$ films reported by Elgun et al., for $\mathrm{Ga}_{1-x} \mathrm{P}_{x}$ $(0.5 \leq x \leq 1)$ prepared by rf sputtering from a phosphorous rich precursor GaP target ${ }^{[2]}$. As the gallium and phosphorous vapour pressures are different, it could be possible that at $T_{\mathrm{s}}=175^{\circ} \mathrm{C}$ a higher phosphorous re-evaporation process takes place, which might result in a lower phosphorous content of the film. However, as we will see in the next sections lower phosphorous content is also observed at lower substrate temperatures (i.e., $T_{\mathrm{s}}=25{ }^{\circ} \mathrm{C}$ ). Then, the lower phosphorous content could be majorly associated with a higher phosphorous thermalization that results in non-stoichiometric $\mathrm{GaP}$ films. Similar results were observed for amorphous gallium arsenide films prepared by $\mathrm{rf}$ sputtering $^{[3]}$.

It is also observed that a small amount of argon $(\sim 2 \%)$ is trapped in the films (Fig. 3(a)), which can be easily explained based on the thermalization effect ${ }^{[25]}$. It is known that during the transport process of the sputtering atoms, one or more components can be thermalized by the collisions with the argon atoms. Since the thermalization of the components is controlled by the product of the argon pressure by the target-substrate distance $\left(p_{\mathrm{Ar}} \times d\right)$, it should be highly sensitive to the argon chamber pressure. In this direction, we have observed that the argon content implanted in the A films decreases as the argon chamber pressure increases, which might result from an increase in the fraction of the thermalized atoms that do not reach substrate.

Fig. 3(b) shows the variation of elemental atomic percentages of $\mathrm{Ga}$ and $\mathrm{P}$ as a function of the argon pressure. The $\mathrm{Ga} / \mathrm{P}$ elemental atomic ratio is found to increase from 1.14 to 1.21 with the increase
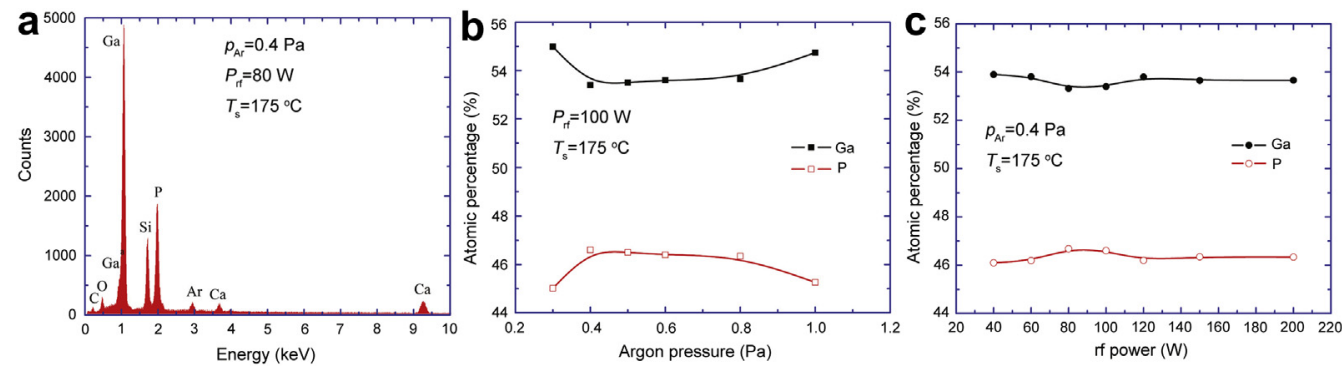

Fig. 3 (a) Representative EDX spectra of GaP thin film deposited under different conditions, (b) variation of Ga and $\mathrm{P}$ atomic percentages as a function of the argon deposition pressure, (c) variation of $\mathrm{Ga}$ and $\mathrm{P}$ atomic percentages as a function of the rf deposition power. 
in argon pressure from 0.4 to $1.0 \mathrm{~Pa}$. This trend can be associated with the dissimilar scattering effect of unequal atomic masses (i.e., $M_{\mathrm{wGa}}=69.723 \mathrm{~g} / \mathrm{mol}$ and $M_{\mathrm{wP}}=30.973 \mathrm{~g} / \mathrm{mol}$ in an argon atmosphere with $M_{\mathrm{wAr}}=39.948 \mathrm{~g} / \mathrm{mol}$ ) and also with the different components thermalization resulting from the collisions with the argon atoms. Thus, it is expectable that a large amount of gallium can be found in the A samples, due to its large atomic mass and lower scattering effect in an argon atmosphere. On the other hand, the lower $\mathrm{Ga} / \mathrm{P}$ atomic ratio (1.14) observed in the sample deposited at $0.4 \mathrm{~Pa}$ could be somehow associated with a lower phosphorous thermalization, resulting from lower phosphorous-argon collisions at this pressure. At the lowest working pressure $(0.3 \mathrm{~Pa})$ the $\mathrm{Ga} / \mathrm{P}$ atomic ratio is 1.22 , which results from the plasma instabilities observed during the deposition process.

Fig. 3(c) shows the variation of elemental atomic percentages of $\mathrm{Ga}$ and $\mathrm{P}$ as a function of the $\mathrm{rf}$ power (B samples). It is observed that there is a weak dependence between the rf power and the composition of the GaP films. For instance, the $\mathrm{Ga} / \mathrm{P}$ atomic ratio decreases from 1.17 to 1.14 with the increase in $\mathrm{rf}$ power from 40 to $80 \mathrm{~W}$, remaining constant up to $100 \mathrm{~W}$. The higher $\mathrm{Ga} / \mathrm{P}$ atomic ratio at lower rf powers is somehow correlated with the lower kinetic energy of the atoms sputtered from the target, which stabilizes around $80 \mathrm{~W}$. As the rf source power is increased from 100 to $200 \mathrm{~W}$, the $\mathrm{Ga} / \mathrm{P}$ atomic ratio presents a slight increase from 1.14 to 1.16 . Although the $\mathrm{Ga} / \mathrm{P}$ atomic ratio practically does not change from 100 to $200 \mathrm{~W}$, the small amount could result from (i) an increase in the components-argon collisions and (ii) an energetic ion bombardment as the rf power increases. The increase in the collisions will favour the phosphorous thermalization and consequently increase the $\mathrm{Ga} / \mathrm{P}$ atomic ratio. On the other hand, an energetic ion bombardment could result in a re-sputtering process where the material with the largest sputtering yield (in this case the phosphorous) will be removed, increasing favourably the $\mathrm{Ga} / \mathrm{P}$ atomic ratio. The results show that GaP films are more stoichiometric when an 80$100 \mathrm{~W}$ rf power is used in their deposition. Other authors have already used similar rf powers in order to obtain stoichiometric $\mathrm{GaP}$ thin films ${ }^{[5]}$.

3.1.3. Electrical properties. The variation of the electrical conductivity of the GaP thin films produced at several argon pressures is shown in Fig. 4(a). The conductivity of the A samples decreases from $4.0 \times 10^{-4}$ to $4.3 \times 10^{-5} \mathrm{~S} \mathrm{~m}^{-1}$ as the argon pressure increases from 0.3 to $1.0 \mathrm{~Pa}$. The evolution of the conductivity of $\mathrm{A}$ samples is consistent with a decrease in the density of defects. Thus, it is expected that the conductivity behaviour of these samples results from a higher scattering and thermalization of the components as the argon pressure increases. As the kinetic energy of the gallium and phosphorous decreases, due to the increase in collisions, the energy of bombardment of the films decreases, reducing the number of defects centres at which hoping conduction occurs ${ }^{[5]}$. Similar trends were reported for amorphous gallium arsenide ${ }^{[26]}$ and amorphous silicon films prepared by rf sputtering in pure argon plasma ${ }^{[27,28]}$.

Fig. 4(b) shows the dependence of the conductivity of the GaP films as a function of the rf deposition power. The conductivity of the B samples increases from $5.5 \times 10^{-5}$ to $\sim 3.0 \times 10^{-4} \mathrm{~S} \mathrm{~m}^{-1}$ as the rf power increases from 40 to $100 \mathrm{~W}$, remaining practically constant for higher rf powers. The increase in the conductivity of the B samples up to $100 \mathrm{~W}$ is consistent with an increase in the density of defects, which is somehow related with the slight decrease in the $\mathrm{Ga} / \mathrm{P}$ atomic ratio. At higher rf powers, a
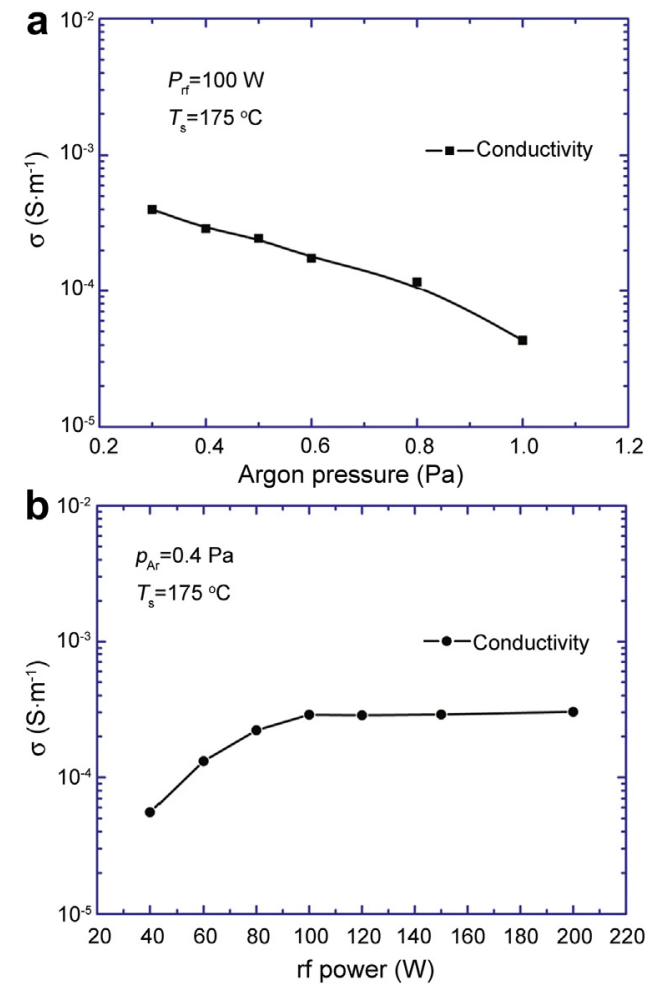

Fig. 4 Conductive behaviour of the a-GaP thin films as a function of: (a) argon deposition pressure, (b) $\mathrm{rf}$ deposition power.

competitive process between the increase in the density of defects and the increase in the $\mathrm{Ga} / \mathrm{P}$ atomic ratio might take place, resulting in a conductivity practically constant. Similar conductive behaviour has been already observed in other III-V type amorphous semiconductors ${ }^{[26]}$

3.1.4. Optical properties. The transmittance and reflectance spectra of three different A samples are shown in Fig. 5(a). They are practically the same up to $\sim 650 \mathrm{~nm}$, showing visible interference processes above $650 \mathrm{~nm}$. The differences in the interference patterns result from the differences in the refraction index of the analysed samples. As the films thickness is maintained constant, it should not influence the interference behaviours observed. Others parameters, like the density of defects and the $\mathrm{Ga} / \mathrm{P}$ atomic ratio could be the responsible for the differences in the interference behaviours.

The optical absorption coefficients $(\alpha)$ of all the sets of samples were obtained from the experimental transmittance and reflectance data, by using an approximate formula derived from the Beer-Lambert's law ${ }^{[21]}$,

$$
T=(1-R)^{2} e^{-\alpha t}
$$

where $t$ is the sample thickness. The nature of the optical transition and the optical band gap for each film was obtained by using Tauc's law ${ }^{[29]}$,

$$
\alpha=\frac{A\left(h \nu-E_{g}\right)^{n}}{h \nu}
$$

where $A$ is a constant, $E_{\mathrm{g}}$ is the optical energy band gap and $n$ is a constant that determines the type of optical transition $(n=1 / 2,3$ / 2,2 or 3 based on whether the optical transition is direct- 

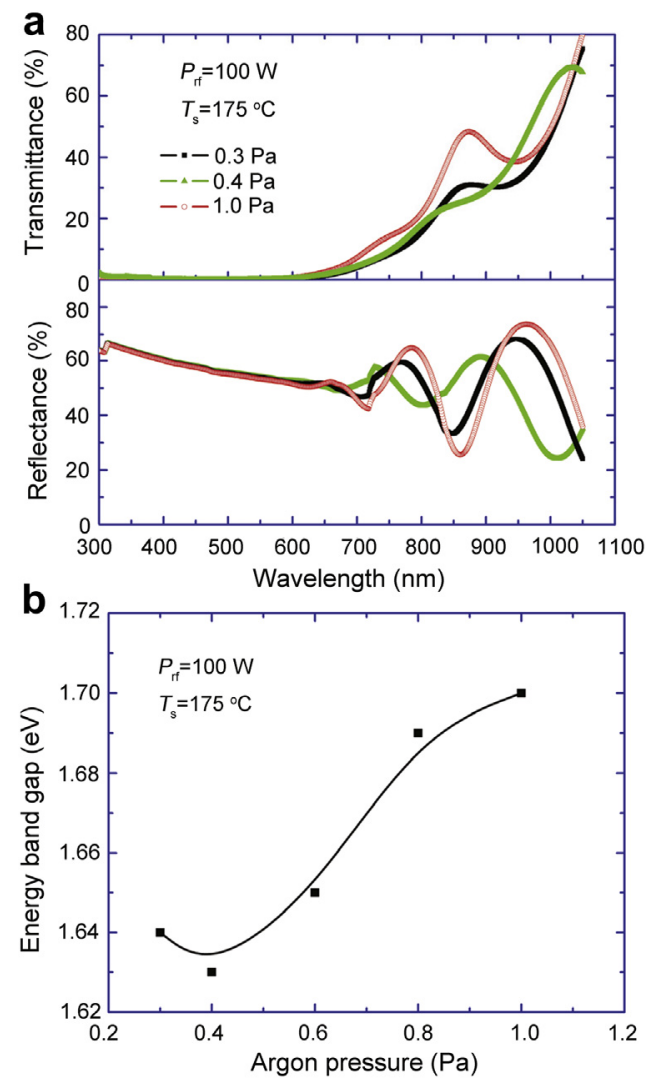

Fig. 5 (a) Transmittance and reflectance of the a-GaP thin films deposited at $0.3,0.4$ and $1.0 \mathrm{~Pa}$ argon deposition pressures, (b) energy band gap of the a-GaP films as a function of the argon deposition pressure.

allowed, direct-forbidden, indirect-allowed or indirect-forbidden, respectively). The values of $\alpha$ are found to obey Eq. (2) for $n=2$, indicating that the optical transitions are indirectallowed, while the intercept $(\nu=0)$ of the extrapolating linear region of $(\alpha h \nu)^{1 / 2} v s h \nu$ plot leads to determine the $E_{\mathrm{g}}$ values $^{[30]}$.

Fig. 5(b) shows the energy band gap of the GaP films as a function of the argon chamber pressure. The $E_{\mathrm{g}}$ of the $A$ samples increases with the increase of argon pressure. As observed in previous analyses, GaP films deposited at higher pressures have less defect centres due to the larger scattering effect and lower density factor, resulting in a decrease of the defect levels in the films. These results are consistent with those reported for $\mathrm{rf}$ deposited amorphous silicon films ${ }^{[27]}$.

Fig. 6(a) shows the transmittance and reflectance spectra of $\mathrm{GaP}$ films deposited at different rf power. The increase in the $\mathrm{rf}$ power from 40 to $200 \mathrm{~W}$ shows no significant changes in the transmittance and reflectance spectra up to $650 \mathrm{~nm}$. Even so, the interference process observed above $650 \mathrm{~nm}$ is singular for each of the three films analysed, showing that there are differences among the refractive index of the films and consequently differences among the defect density of states, which results from the increase of the rf deposition power.

The variation of the optical band gap for the GaP films deposited at different rf powers is shown in Fig. 6(b). Increasing the rf power from 40 to $200 \mathrm{~W}$ results in a decrease of the optical band gap (from 1.70 to $1.62 \mathrm{eV}$ ). If defect density of the film increases, additional states in the vicinity of the band edge will appear, causing a smaller effective band edge. This result is
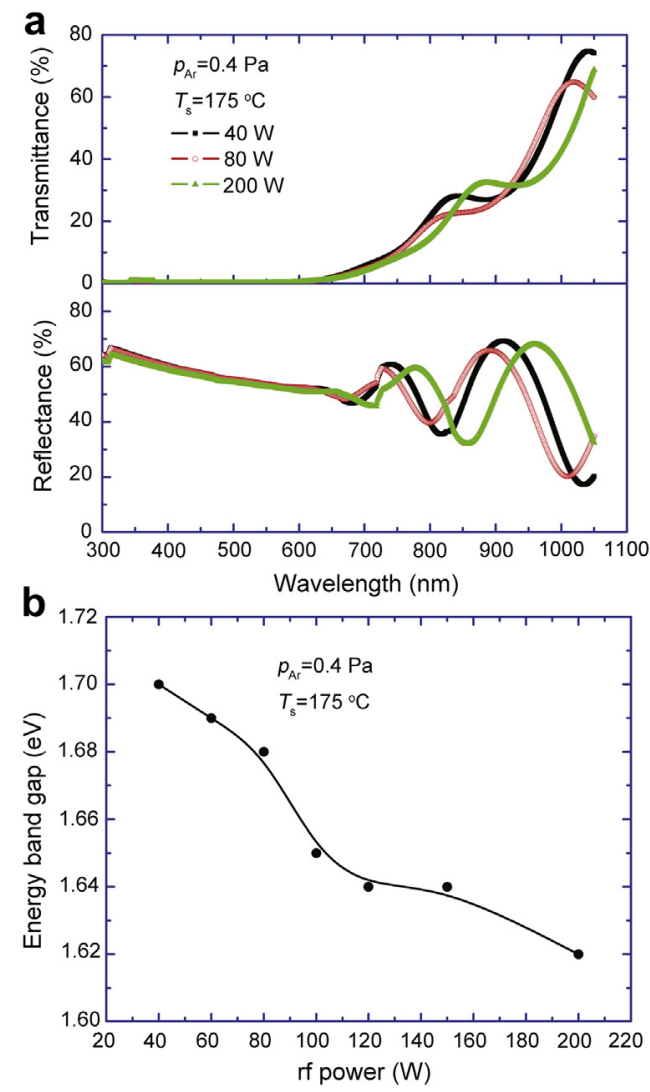

Fig. 6 (a) Transmittance and reflectance of the a-GaP thin films deposited at 40, 80 and $200 \mathrm{~W}$ rf deposition powers, (b) energy band gap of the a-GaP films as a function of the rf deposition power.

consistent with the conductivity analysis, which shows that the increase in the rf power results in an increase of the kinetic energy and hence an increase of the defect density of the films.

\subsection{GaP crystalline films}

3.2.1. Structural analysis. The $X$-ray diffraction patterns of the GaP films deposited by varying the substrate temperature from 25 up to $400{ }^{\circ} \mathrm{C}$, while keeping the rf source power constant at $80 \mathrm{~W}$ and the argon gas pressure at $0.4 \mathrm{~Pa}$ (C samples), are shown in Fig. 7. Below $200{ }^{\circ} \mathrm{C}$, the films show a-GaP phase overlapped with weak diffraction peaks, corresponding to $\mathrm{Ga}$ phase. On the other hand, the films grown at $T_{\mathrm{s}}>200{ }^{\circ} \mathrm{C}$ exhibit the formation of $\mathrm{GaP}$ crystalline phase, with residual peaks of $\mathrm{Ga}$ phase. The GaP phase is characterized by the peaks localized at $2 \theta=28.1^{\circ}, 46.4^{\circ}$ and $55.05^{\circ}$ that correspond to (111), (220) and (311) orientations, respectively, as reported by Voitsekhovskii and Panchenko ${ }^{[31]}$, while the peaks observed at $2 \theta=43.7^{\circ}$, $51.1^{\circ}$ and $72.99^{\circ}$ correspond to the (111), (221) and (151) orientations of a residual Ga metallic phase ${ }^{[23,24]}$. Moreover, a weak $\mathrm{X}$-ray peak is localized at $2 \theta=26.6^{\circ}$, which is only indexable as a $(10 \overline{10})$ in the hexagonal wurtzite structure of $\mathrm{GaP}^{[10]}$. The $\mathrm{Ga}$ metallic phase was practically suppressed at $T_{\mathrm{s}}=250$ and $300{ }^{\circ} \mathrm{C}$ where the films are polycrystalline, exhibiting a cubic structure with strong (220) orientation. The Ga X-ray reflexions observed in the films deposited at substrate temperatures higher than $300{ }^{\circ} \mathrm{C}$ are more intense, due to the predictable phosphorous re-evaporation. 


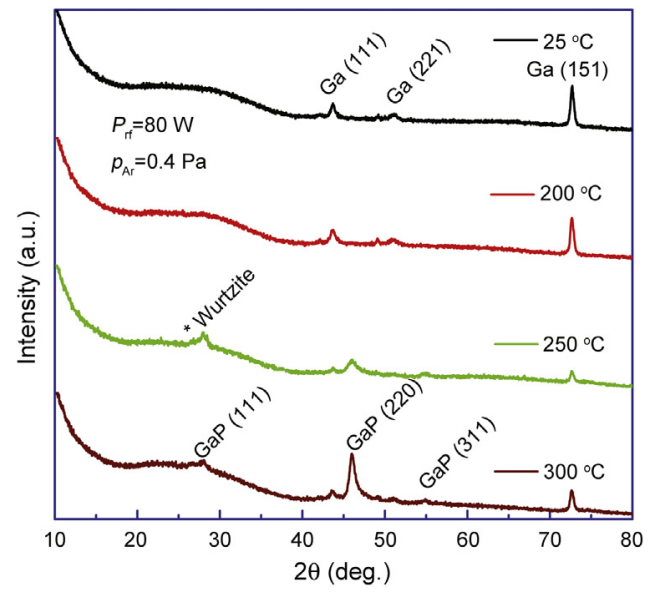

Fig. 7 X-ray spectra of GaP thin films deposited at different substrate deposition temperatures.

It was previously reported by some authors that around $250{ }^{\circ} \mathrm{C}$ is the ideal substrate temperature in order to transit from an amorphous-to-crystalline $\mathrm{GaP}$ phase formation ${ }^{[10,12,19]}$, which is consistent with the results obtained in this work. In other direction, Li et al. ${ }^{[22]}$ reported that a single polycrystalline (111) orientated $\mathrm{GaP}$ phase is obtained when the films prepared by $\mathrm{rf}$ sputtering are deposited at a substrate temperature of $\sim 390{ }^{\circ} \mathrm{C}$. However, they used zinc sulphide as substrate, which practically has the same lattice parameter of the $\mathrm{GaP}$ films and consequently the same X-ray reflections.

The origin of strain in thin films is majorly associated with crystallization processes and differences in thermal expansion coefficients of the substrate and polycrystalline film at a particular deposition temperature. They can influence the properties of the films due to intrinsic and extrinsic lattice distortions resulting from the film crystallization and the substrate clamping, respectively. The percentage of tensile or compressive strain in polycrystalline films can be evaluated by using the following relation $^{[30]}$,

$$
\operatorname{Strain}(\%)=\frac{a-a_{0}}{a_{0}} \times 100
$$

where $a$ is the lattice constant of polycrystalline GaP films and $a_{0}$ is the unstrained bulk GaP lattice parameter $(0.5473 \mathrm{~nm})$.

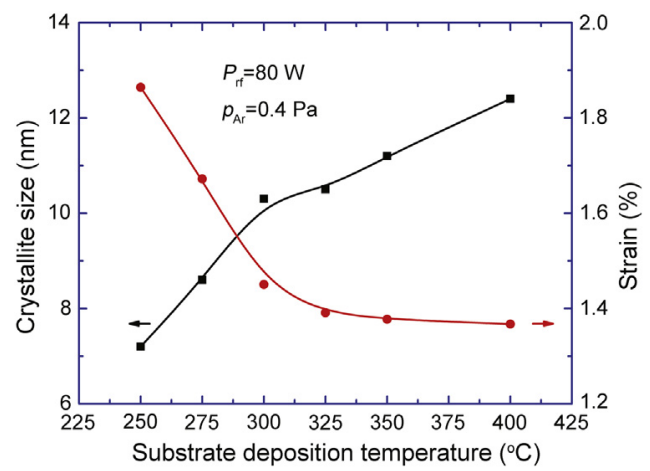

Fig. 8 Variation of crystallite size and strain in GaP films as a function of the substrate deposition temperature.

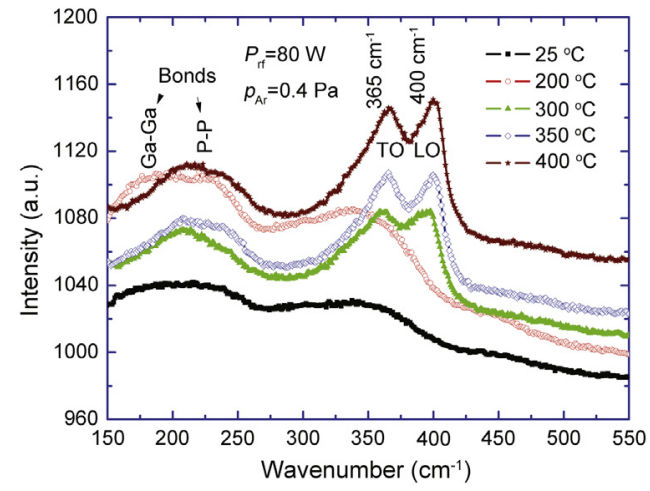

Fig. 9 Raman spectra of $\mathrm{GaP}$ thin films deposited at different temperatures.

The crystallite size is evaluated by using the Debye-Scherrer equation $^{[29]}$,

$$
D=\frac{k \lambda}{\beta \cos \theta}
$$

where $D$ is the crystallite size, $k$ is the crystallite shape factor, $\lambda$ is the $\mathrm{X}$-ray wavelength, $\beta$ is the $\mathrm{X}$-ray diffraction broadening and $\theta$ is the observed peak angle. Fig. 8 shows the variation of the strain (\%) in polycrystalline $\mathrm{GaP}$ films deposited at $T_{\mathrm{s}}$ between 250 and $400{ }^{\circ} \mathrm{C}$ by keeping the $\mathrm{rf}$ power $(80 \mathrm{~W})$ and argon pressure $(0.4 \mathrm{~Pa})$ constant. It was observed that the tensile strain in the films decreases with increasing $T_{\mathrm{s}}$. Although there is a substrate contribution, this effect is observed due to the recrystallization that takes place in polycrystalline films during the deposition process, leading to an increase of the crystallite size and lattice defects annihilation.

Fig. 9 shows the Raman analysis of selected C samples. It is visible that wide bands in the films deposited at $T_{\mathrm{s}}<250{ }^{\circ} \mathrm{C}$ are associated with gallium and phosphorous bonding, typical of amorphous III-V compounds ${ }^{[26]}$. However, the Raman patterns of the films deposited at $T_{\mathrm{s}} \geq 250{ }^{\circ} \mathrm{C}$ show the first-order scattering from longitudinal optical $\left(400 \mathrm{~cm}^{-1}\right)$ and transverse optical $\left(365 \mathrm{~cm}^{-1}\right)$ phonons of a polycrystalline $\mathrm{GaP}$ films ${ }^{[20]}$.

3.2.2. Compositional analysis. The EDS spectra of GaP thin films (see representative Fig. 3(a)) revealed that the substrate temperature has a significant influence on the composition of the films, as shown in Fig. 10. The $\mathrm{Ga} / \mathrm{P}$ atomic ratio decreases

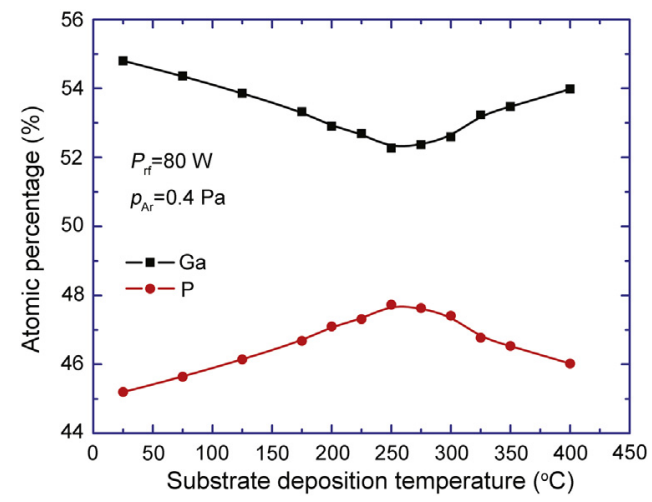

Fig. 10 Variation of $\mathrm{Ga}$ and $\mathrm{P}$ atomic percentages as a function of the substrate deposition temperature. 

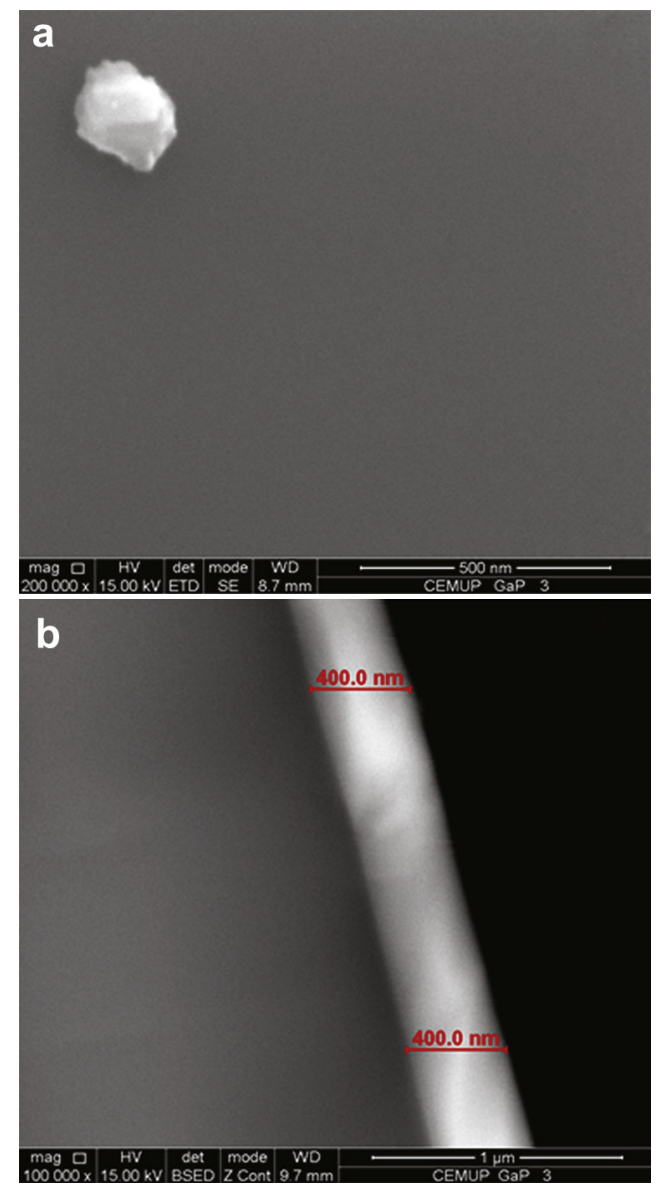

Fig. 11 (a) Plan-view and (b) SEM images of representative crosssection of the GaP films prepared under different deposition conditions.

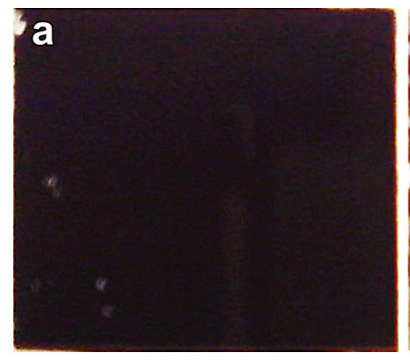

$T_{\mathrm{s}}=25^{\circ} \mathrm{C}$

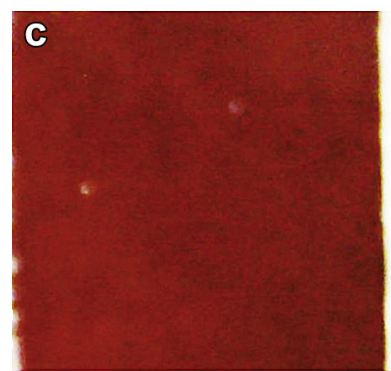

$T_{\mathrm{s}}=300^{\circ} \mathrm{C}$

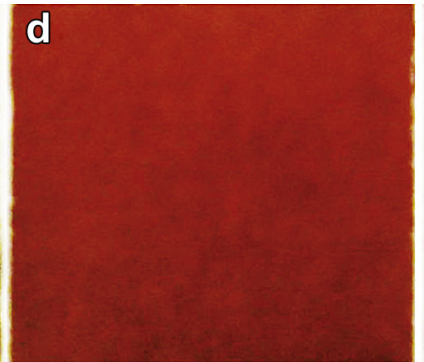

$T_{\mathrm{s}}=350^{\circ} \mathrm{C}$

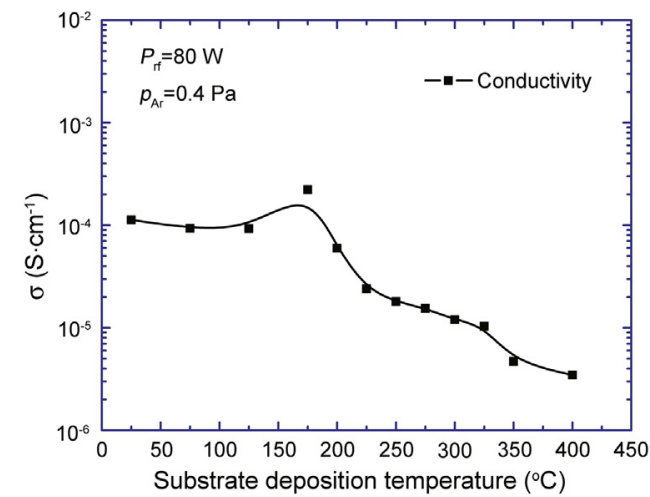

Fig. 13 Conductive behaviour of the GaP thin films as a function of the substrate deposition temperature.

progressively from 1.21 to 1.09 with increasing substrate temperature from room temperature up to $250{ }^{\circ} \mathrm{C}$, remaining practically constant up to $300{ }^{\circ} \mathrm{C}$. Above this temperature, $\mathrm{Ga} / \mathrm{P}$ atomic ratio increases up to 1.17 as the substrate temperature increases. This behaviour can be easily explained if we take it into account that even at low temperatures the phosphorous reevaporation process takes place. As the substrate temperature increases, the $\mathrm{Ga}-\mathrm{P}$ bonds are improved which results in a lower phosphorous re-evaporation and consequently a reduction of $\mathrm{Ga} /$ $\mathrm{P}$ atomic ratio. When the temperatures are higher than $300{ }^{\circ} \mathrm{C}$, the $\mathrm{Ga} / \mathrm{P}$ atomic ratio increases, which is consistent with the evaporation of phosphorous from the surface before it is bonded to the GaP crystalline structure.

3.2.3. Surface morphology. An SEM plan-view and crosssection images of the GaP film deposited at $p_{\mathrm{Ar}}=0.4 \mathrm{~Pa}$, $P_{\text {rf }}=80 \mathrm{~W}$ and $T_{\mathrm{s}}=300{ }^{\circ} \mathrm{C}$ are shown in Fig. 11 . The surface morphology of the film is continuous, smooth and uniform and it is not affected when the deposition conditions (argon pressure, $\mathrm{rf}$ source power and substrate temperature) are changed. Although the crystallization of the films occurs at $T_{\mathrm{s}}>250^{\circ} \mathrm{C}$, the grain

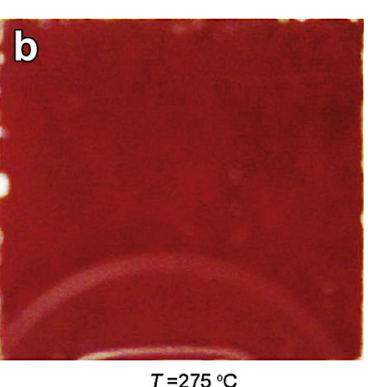

$T_{\mathrm{s}}=275^{\circ} \mathrm{C}$

Fig. 12 Optical images of the GaP films deposited at $25,275,300,350$ and $400{ }^{\circ} \mathrm{C}$, keeping constant $p_{\text {Ar }}(0.4 \mathrm{~Pa})$ and $P_{\text {rf }}(80 \mathrm{~W})$. 


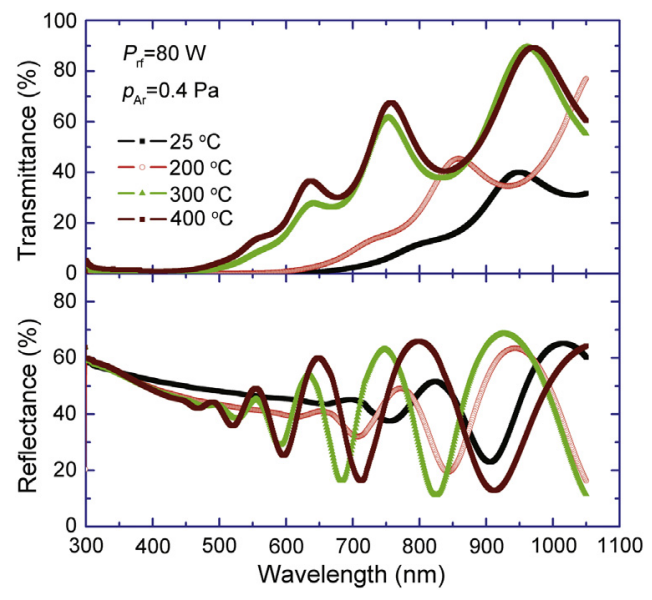

Fig. 14 Transmittance (a) and reflectance (b) of the GaP thin films deposited at $25,200,300$ and $400{ }^{\circ} \mathrm{C}$.

size is in the limit of resolution of the SEM. Moreover, the presence of a gallium phase in grain boundary also interferes with the determination of the grain size. Similar results were obtained for GaP films deposited on glass and boron doped silicon substrates by liquid phase epitaxy ${ }^{[4,16]}$.

The optical analysis of the $\mathrm{C}$ samples shows that the GaP films, deposited at substrate temperatures below $250{ }^{\circ} \mathrm{C}$, are nontransparent and exhibit a metallic shiny appearance (Fig. 12). However, when the substrate deposition temperature is increased above $250{ }^{\circ} \mathrm{C}$, the metallic-appearance disappears and the films reach the light red colour of bulk GaP target. Similar behaviour was already reported by Davey and Pankey ${ }^{[10]}$ and Barbe and $\mathrm{Saks}^{[12]}$ for a-GaP films deposited by vacuum evaporation technique at substrate temperatures less than $270{ }^{\circ} \mathrm{C}$, obtaining nontransparent films with metallic appearance.
3.2.4. Electrical properties. The variation of the conductivity of the $\mathrm{GaP}$ thin films deposited at different substrate temperatures is shown in Fig. 13. The conductivity values of the $\mathrm{C}$ samples decrease from $1.13 \times 10^{-4}$ to $3.46 \times 10^{-6} \mathrm{~S} \mathrm{~m}^{-1}$ with increasing substrate deposition temperature from 25 to $400{ }^{\circ} \mathrm{C}$. As above-mentioned, all the samples are Ga-rich. However, at lower deposition temperatures $\left(25{ }^{\circ} \mathrm{C}<T_{\mathrm{s}}<200{ }^{\circ} \mathrm{C}\right)$, the $\mathrm{C}$ samples show a visible phosphorous evaporation that results in unreacted gallium surface segregations and consequently relatively higher conductivity values. On the other hand, at $200{ }^{\circ} \mathrm{C} \leq T_{\mathrm{s}} \leq 300{ }^{\circ} \mathrm{C}$, the conductivity of the films decreases progressively, which associates with the elimination of defects. This behaviour is consistent with a higher $\mathrm{Ga}-\mathrm{P}$ interaction and with a crystallization of the films in this temperature range. Above $300{ }^{\circ} \mathrm{C}$, the crystallinity of the films is improved, which results in a rapid fall of the $\mathrm{GaP}$ conductivity. An identical trend was obtained by Elgun and Davis ${ }^{[8]}$ in rf sputtering of a-GaP thin films in the $T_{\mathrm{s}}$ range of $20-270{ }^{\circ} \mathrm{C}$.

3.2.5. Optical properties. The transmittance and reflectance spectra for GaP films deposited at different substrate temperatures are shown in Fig. 14. Significant changes were observed in the optical reflectance and transmittance of the $\mathrm{C}$ samples close to the absorption edge of the films as the deposition temperature is increased, mainly due to the elimination of defects and the crystallization of the films which results in colorization changes (Fig. 12). For instance, in the amorphous region $\left(T_{\mathrm{s}}<250{ }^{\circ} \mathrm{C}\right)$, the GaP films showed transmittances $<15 \%$ at $700 \mathrm{~nm}$ and exhibited large optical absorption-edge shifts. On the other hand, there is a progressive shift in the transmittance and absorption edges to lower $\lambda$ as the substrate deposition temperature increases from 250 to $300^{\circ} \mathrm{C}$. As above-mentioned, this behaviour is associated with the elimination of defects and the crystallization of the films in this region which results in an elimination of the metallic appearance of the films. Finally, at higher

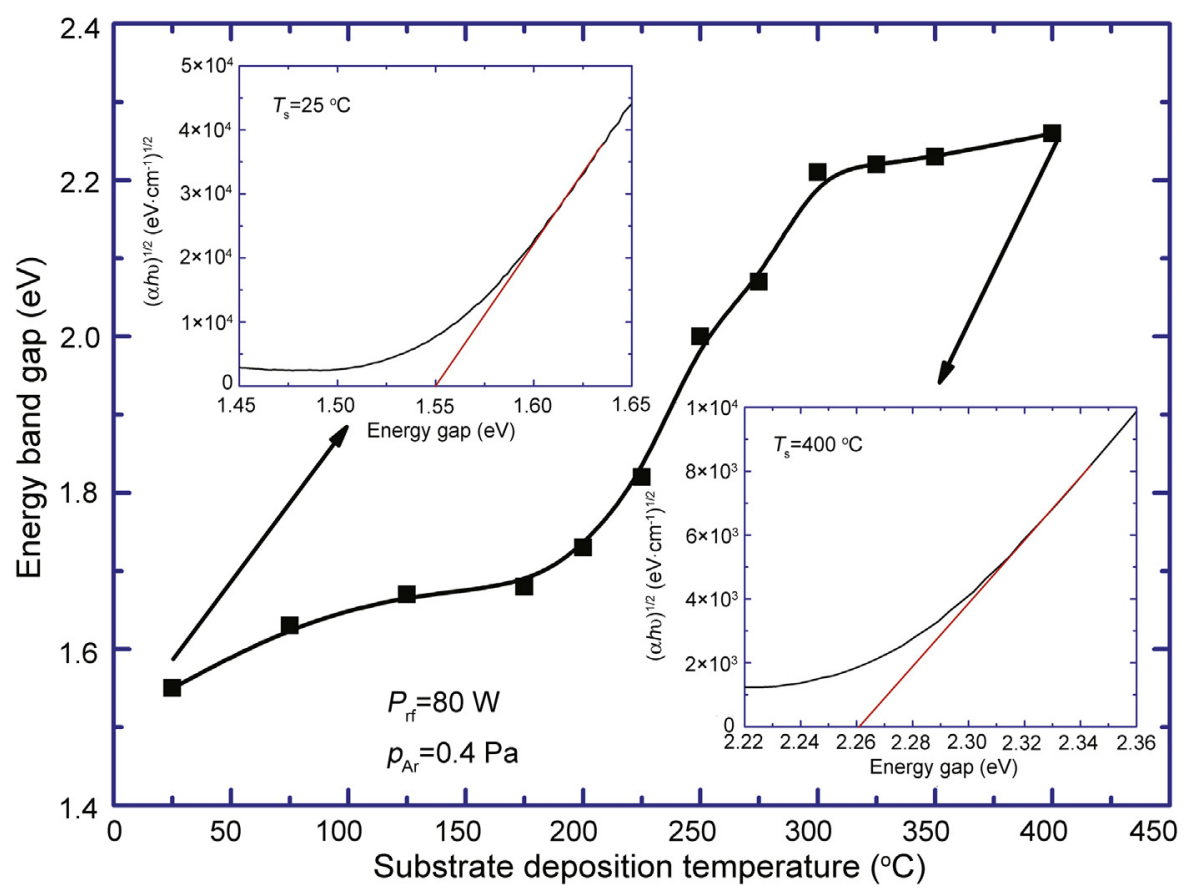

Fig. 15 Energy band gap of the GaP films as a function of the deposition temperature and $(\alpha h \nu)^{1 / 2} v s h v$ curves of GaP films deposited at 25 and $400{ }^{\circ} \mathrm{C}$ (inset). 
substrate deposition temperature (i.e., $400{ }^{\circ} \mathrm{C}$ ), the films showed transmittance of $\sim 20 \%$ and absorption of $\sim 45 \%$ at $550 \mathrm{~nm}$ which is consistent with the results reported for the bulk $\mathrm{GaP}$ material $^{[8]}$.

Fig. 15 shows the variation of the energy gap with substrate temperature, while the inset plots show the plots of $(\alpha h \nu)^{1 / 2} v s h \nu$ for films deposited at $T_{\mathrm{s}}=25{ }^{\circ} \mathrm{C}$ and $400{ }^{\circ} \mathrm{C}$. The $E_{\mathrm{g}}$ of the $\mathrm{C}$ samples increases from 1.55 to $2.26 \mathrm{eV}$ with increasing substrate temperature from 25 up to $400{ }^{\circ} \mathrm{C}$. It is perceptible that films deposited at lower substrate temperatures contain several defect levels in the valence and/or conduction bands which result in higher conductive behaviour, and hence a smaller effective band edge. Increasing the substrate thermal energy, the density of defects in the deposited films decreases, shifting the highest occupied valence band and the lowest unoccupied conduction band to more negative and positive values, respectively, which results in the widening of the band gap of the films. An identical trend was obtained by Murali and Gopalam ${ }^{[13]}$ for evaporated $\mathrm{GaP}$ films grown at different substrate temperatures, showing a close value of $E_{\mathrm{g}}$ for the film deposited at $T_{\mathrm{s}}=250{ }^{\circ} \mathrm{C}$.

\section{Conclusion}

GaP films deposited at temperatures lower than $250{ }^{\circ} \mathrm{C}$ are amorphous and show a residual gallium metallic phase. It is found that the argon pressure and the rf power affect significantly the structural, electrical and optical properties of the GaP films deposited at $175^{\circ} \mathrm{C}$. The increase in argon partial pressure results in a slight increase of the residual gallium metallic phase, a decrease of the defects and conductivity of the films and an improvement of the energy band gap of these films. On the other hand, the increase of the rf source power shows a mixed trend. The structural, electrical and optical properties of these films are improved up to $100 \mathrm{~W}$ and begin to deteriorate at higher $\mathrm{rf}$ powers. Crystalline GaP films are obtained when the substrate temperatures of $250^{\circ} \mathrm{C}$ or higher are used in deposition process. The increase of the deposition temperature above $250{ }^{\circ} \mathrm{C}$ results in an increase of the crystallite size, a decrease of the internal strain, a decrease of the defects and the conductivity of the films and an improvement of the energy band gap, reaching the bulk band gap at $T_{\mathrm{s}} \geq 300{ }^{\circ} \mathrm{C}$. In short, this study shows the optimal conditions to prepare amorphous and crystalline GaP films, revealing that the rf deposition method could be suitable for the preparation of active layers of thin film multijunction solar cells.

\section{Acknowledgements}

This work was supported by the ERDF (European Regional Development Fund) through the COMPETE Programme (operational programme for competitiveness) and by the Portuguese National Strategic Reference Framework (NSRF) through the project CFC-5568. Authors thank the technical assistance of MSc. J. Oliveira and the helpful comments of Professor A.P. Leite.

\section{REFERENCES}

[1] N. Pimpabute, T. Burinprakhon, W. Somkhunthot, Opt. Appl. 41 (2011) 257-258

[2] N. Elgun, S.J. Gurman, E.A. Davis, J. Phys. Condens. Matter 12 (2000) 4723-4733.

[3] J. Seguin, B. Hadadi, H. Carchano, K. Aguir, J. Non-Cryst. Solids 238 (1998) 253-258.

[4] X. Lu, S.R. Huang, R.L. Opila, A. Barnett, in: Proceedings to the 34th IEEE Photovoltaic Specialists Conference, Philadelphia, USA, June 7-12, 2009.

[5] J. Gao, Q. Zhan, A.M. Sarangan, Thin Solid Films 519 (2011) $5424-5428$.

[6] M. Yamaguchi, T. Takamoto, A. Khan, M. Imaizumi, S. Matsuda, N.J. Ekins-Daukes, Prog. Photovolt: Res. Appl. 13 (2005) $125-132$.

[7] H. Kubota, T. Tashiro, T. Hiyayu, T. Chikushima, T. Fujiyoshi, R. Miyagawa, M. Onuki, in: Proceedings to the 24th IEEE Photovoltaic Specialists Conference, Waikoloa, Hawaii, December 5-9, 1994.

[8] N. Elgun, E.A. Davis, J. Phys. Condens. Matter 6 (1994) 779-790.

[9] J. Nelson, The Physics of Solar Cell, first ed., Imperial College Press, United Kingdom, 2003.

[10] J.E. Davey, T. Pankey, J. Appl. Phys. 40 (1969) 212-219.

[11] J.H. Xu, K.J. Chen, E.J. Zhu, Chin. Phys. Lett. 8 (1991) $187-190$

[12] D.F. Barbe, N.S. Saks, J. Appl. Phys. 44 (1973) 1666-1672.

[13] K.R. Murali, B.S.V. Gopalam, Surf. Coat. Technol. 30 (1987) 327-331.

[14] A.M. Zykov, B.E. Samorukov, Sov. Phys. J. 14 (1971) 761-764.

[15] J.C. Knights, R.A. Lujan, J. Appl. Phys. 49 (1978) 1291-1293.

[16] S.R. Huang, X. Lu, A.M. Barnett, R.L. Opila, in: Proceedings to the 34th IEEE Photovoltaic Specialists Conference, Philadelphia, USA, June 20-25, 2009.

[17] N. Elgun, E.A. Davis, J. Non-Cryst. Solids 330 (2003) 226-233.

[18] N. Elgun, S.J. Gurman, E.A. Davis, J. Phys. Condens. Matter 4 (1992) 7759-7772.

[19] K. Starosta, J. Zelinka, D. Berková, J. Kohout, Thin Solid Films 61 (1979) 241-248.

[20] A.P. Mora, M.M. Lira, S.J. Sandoval, M.L. López, Phys. Stat. Sol. B 242 (2005) 1887-1891.

[21] J. Sosniak, J. Vac. Sci. Technol. 7 (1970) 110-114.

[22] Y.P. Li, Z.T. Liu, J. Mater. Sci. Technol. 26 (2010) 93-96.

[23] H. Curien, A. Rimsky, A. Defrain, Bull. Soc. Fr. Mineral. Crystallogr. 84 (1961) 260-264.

[24] G. Bruzzone, Boll. Sci. Fac. Chim. Ind. Bologna 24 (1966) $113-132$.

[25] A. Gras-Marti, J.A. Valles-Abarca, J.C. Moreno-Martin, in: Proceedings to the Plasma Surface Interactions and Processing of Materials, 1990. NATO ASI Series.

[26] B. Hadadi, H. Carchano, J. Seguin, H. Tijani, Vacuum 80 (2005) 272-283.

[27] W.T. Pawlewicz, J. Appl. Phys. 49 (1978) 5595-5601.

[28] T. Shimizu, M. Kumeda, I. Watanabe, K. Kamono, Jpn. J. Appl. Phys. 18 (1979) 1923-1929.

[29] G.H. Yue, D.L. Peng, P.X. Yan, L.S. Wang, W. Wang, X.H. Luo, J. Alloy. Compd. 468 (2009) 254-257.

[30] G.H. Chandra, J. Perez de la Cruz, J. Ventura, Semicond. Sci. Technol. 26 (2011) 075017-075024.

[31] A.V. Voitsekhovskii, L.B. Panchenko, Inorg. Mater. 13 (1977) $137-140$. 